\title{
Enhanced desorption of surface methyl groups in time- resolved chemical vapour deposition of aluminium nitride from trimethylaluminum
}

\author{
Polla Rouf*[1], Pitsiri Sukkaew[1], Adam Hultqvist [2], Tobias Törndahl [2], Lars Ojamäe[1], \\ Henrik Pedersen[1] \\ [1] Department of Physics, Chemistry and Biology, Linköping University, SE-581 83 \\ Linköping, Sweden \\ [2] Department of Materials Science and Engineering, Div. Solar Cell Technology, Uppsala \\ University, SE-751 21 Uppsala, Sweden \\ *Corresponding author, e-mail: polla.rouf@liu.se
}

\begin{abstract}
Aluminium nitride (AlN) is a semiconductor with a wide range of applications from light emitting diodes to high frequency transistors. Electronic grade AIN is routinely deposited at $1000{ }^{\circ} \mathrm{C}$ by chemical vapour deposition (CVD) using trimethylaluminium (TMA) and $\mathrm{NH}_{3}$ while low temperature CVD routes to high quality AlN are scares and suffer from high levels of carbon impurities in the film. We report on an ALD-like CVD approach with time-resolved precursor supply where thermally induced desorption of methyl groups from the AlN surface is enhanced by the addition of an extra pulse, $\mathrm{H}_{2}, \mathrm{~N}_{2}$ or Ar between the TMA and $\mathrm{NH}_{3}$ pulses. The enhanced desorption allowed deposition of AlN films with carbon content of 1 at. $\%$ at 480 ${ }^{\circ} \mathrm{C}$. Mass spectrometry combined with kinetic- and quantum chemical modelling show that the extra pulse between TMA and $\mathrm{NH}_{3}$ enhances the desorption and prevents re-adsorption of the methyl groups, terminating the AlN surface after the TMA pulse. The surface methyl groups are found to desorb as $\mathrm{CH}_{3}, \mathrm{CH}_{4}$ and $\mathrm{C}_{2} \mathrm{H}_{x}$.
\end{abstract}

\section{Introduction}

Aluminium nitride (AlN) is a widely used semiconductor material in several electronic devices 1 due to its direct wide bandgap of $6.2 \mathrm{eV}_{2}$. The conventional method for depositing epitaxial films of $\mathrm{AlN}$ is chemical vapor deposition (CVD) using trimethylaluminium (TMA), $\mathrm{Al}_{2}\left(\mathrm{CH}_{3}\right)_{6}$ and ammonia, $\mathrm{NH}_{3}$, at temperatures, typically, above $1000^{\circ} \mathrm{C}_{3}$. This limits the applications for AlN to substrates and underlying film materials that can withstand such temperatures. An alternative low temperature deposition route is atomic layer deposition (ALD), which is a timeresolved form of CVD where the $\mathrm{Al}$ and $\mathrm{N}$ precursors are pulsed into the deposition chamber sequentially, separated by inert gas pulses. This gas pulsing makes the process solely depend on surface chemical reactions and omits gas phase chemical reactions, which typically need 
high temperatures. ALD of AlN have previously been reported using TMA with $\mathrm{NH}_{3}$ both via thermal4,5,6, $\mathrm{NH}_{3}$ plasma7,8,9,10 and $\mathrm{N}_{2}$ plasma11 routes. Plasma processes can lead to crystalline and conformal AlN films at temperatures $<300{ }^{\circ} \mathrm{C} .9,10$ To obtain a crystalline AlN film via the thermal route, a temperature $>375^{\circ} \mathrm{C}$ is needed.5,6

The TMA molecule is reported to decompose above $330{ }^{\circ} \mathrm{C}_{12}$, with the breaking of one of the Al-C bonds, forming dimethyl aluminium (DMA) and a methyl group at temperatures $\leq 500$ ${ }^{\circ} \mathrm{C} .13$ Thermal ALD of AlN typically contain 5-10 at.\% $\mathrm{C}$ depending on the deposition temperature,4,6 making thermal ALD routes not ideal for depositing electronic grade AlN. Plasma ALD is also associated with high levels of carbon impurities as atomic hydrogen, produced in the plasma discharge, can induce a chemistry trapping carbon impurities in the film by abstracting $\mathrm{H}_{2}$ from surface methyl groups.14 Deposition of crystalline AlN with low levels of carbon is thus dependent on an efficient carbon cleaning surface chemistry.

Herein, we report a low temperature, ALD-like, CVD approach depositing AlN using TMA and $\mathrm{NH}_{3}$ delivered in separate pulses at $480{ }^{\circ} \mathrm{C}$. We show that adding an extra gas pulse, with the gas flow perpendicular to the substrate surface between the TMA and $\mathrm{NH}_{3}$ pulses, leads to a drastic decrease in $\mathrm{C}$ content and increases the crystalline quality of the films. Mass spectrometry, quantum-chemical density functional theory and kinetic modelling show that the lower carbon content in the films is attributed to enhanced desorption which prevents readsorption of methyl groups to the AlN surface.

\section{Methods}

\section{Film deposition}

The AlN films were deposited in a Picosun R-200 ALD system with a base pressure of $400 \mathrm{~Pa}$ and continuous $\mathrm{N}_{2}$ (99.999\%, further purified with a getter filter to remove moisture) flow through the deposition chamber. The chamber walls and the substrate holder were heated using separate heating systems. Si (100) wafers without further cleaning were cut into $15 \times 15 \mathrm{~mm} 2$ pieces and used as substrates. The pieces were loaded into the deposition chamber without using a load-lock. Commercially available TMA (Pegasus Ltd, Alpha grade) in a stainless-steel bubbler was used at room temperature with $100 \mathrm{sccm} \mathrm{N_{2 }}$ as carrier gas. $\mathrm{NH}_{3}$ (AGA/Linde, $99.999 \%$ ) was used as the nitrogen source in the process. The TMA pulse time was set at $0.1 \mathrm{~s}$ with 6 s purge and the $\mathrm{NH}_{3}$ pulse time was set to $12 \mathrm{~s}$ with 6 s purge if nothing else is stated. $\mathrm{H}_{2}$ (99.999\%, further purified with a getter filter to remove moisture), $\mathrm{N}_{2}$ or $\operatorname{Ar}$ (99.999\%, further purified with a getter filter to remove moisture) was used as a cleaning pulse between the TMA and $\mathrm{NH}_{3}$ pulse. It should be noted that the flow of these cleaning pulses $(150 \mathrm{sccm})$ was perpendicular to the substrate surface compared to horizontal for the purge pulses. The 
difference between the cleaning pulse and the purge, beside the flow direction, is also the flow rate were the purge gas $\left(\mathrm{N}_{2}\right)$ had a total flow of $500 \mathrm{sccm}$ (continuous flow into the reaction chamber) distributed over the six gas lines, were all the six gas lines had the same flow expect one which is the main $\mathrm{N}_{2}$ line into the chamber with a flow of $200 \mathrm{sccm}$. While the cleaning pulse had a flow of $150 \mathrm{sccm}$ independent of which gas was used.

A second, homebuilt ALD reactor with an integrated quadrupole mass spectrometer, QMS, (MKS, Spectra Microvision Plus) was used to analyse the composition of the gas phase from the studied surface reactions. The small ALD chamber consists of $1075 \times 25 \mathrm{~mm} 2$ quartz slides, stacked in a sandwich structure, allowing the precursors to pass between the substrates and thereby increasing the total surface area for the chemical reactions. The QMS cell is differentially pumped and samples the gas phase through an orifice placed a few $\mathrm{cm}$ downstream of the quartz slides. Glass slides coated with AlN by the ALD process described above were used as substrates for this study. The ALD chamber was heated to $350{ }^{\circ} \mathrm{C}$ and the total pressure was set to 1 Torr by using $10 \mathrm{sccm}$ Ar and a regulating valve. The corresponding pressure in the QMS cell was measured to be 5x10-5 Torr. For the experiment, TMA (SAFC, electronic grade) was introduced into the reaction chamber to saturate all surfaces, where after it was turned off and changes in the gas composition was monitored by the mass spectrometer (MS).

\section{Characterisation}

The crystallinity of deposited films was studied using a PANalytical EMPYREAN MRD XRD with a $\mathrm{Cu}$-anode $\mathrm{x}$-ray tube and 5-axis (x-y-z-v-u) sample stage in grazing incidence (GIXRD) configuration with a 0.5 o incident angle. PANalytical X'Pert PRO with a $\mathrm{Cu}$-anode tube and Bragg-Brentano HD optics was used for X-ray Reflectivity (XRR) mode to measure the thickness of the films. From the XRR measurements the software PANalytical X'Pert reflectivity was used to fit the data using a two-layer model, AlN/substrate. A LEO 1550 Scanning electron microscopy (SEM) with an acceleration energy of 10-20 kV was used to study the morphology of the films. Kratos AXIS Ultra DLD X-ray photoelectron spectroscopy (XPS) equipped with Ar sputtering was used to analyse the composition (5\% error margin) and chemical environments in the films. The composition of the films was obtained after clean sputtering the surface with a sputtering power of $0.3 \mathrm{eV}$ for $600 \mathrm{~s}$. CasaXPS software was used to evaluate the data. Gaussian-Laurentius functions and Shirley background were used to fit the experimental XPS data. 


\section{Computational details}

Quantum-chemical density functional theory (DFT) computations were applied to study the mechanism of surface desorption of methyl groups on the AlN surface. The calculations were performed using the Perdew-Burke-Ernzerhof (PBE)15,16 generalized gradient approximation (GGA) functional together with Grimme D3-empirical dispersion correction17 using the Vienna Ab initio Simulation Package (VASP)18. For the representation of pseudopotentials for Al, N, $\mathrm{C}$ and $\mathrm{H}$ the projected augmented wave (PAW) method19,20 provided by that package was used, where in the surface studies a fractional charge of $0.7521,22$ was used for the $\mathrm{H}$ atoms bonded to the $\mathrm{N}$ atoms at the bottom (opposite side) terminated surface layer to facilitate the saturation of dangling bonds. The hexagonal unit cell of the bulk AlN structure was first derived by energy minimization with respect to the lattice parameters and coordinates using a $7 \times 7 \times 7$ grid of gamma-centred k-points, resulting in $a=3.114 \AA$ and $c=4.995 \AA$. Then a model of a 2dimensional surface was constructed by cutting out a slab of $5(\mathrm{Al}, \mathrm{N})$ layers orthogonal to the $c$-direction (corresponding to a vertical height of about $10.6 \AA$ from a "top" Al to a "bottom" $\mathrm{N}$ ), with a hexagonal surface (2-dimensional) unit cell with $a_{\text {surf }}=3.114 \AA$ (and with the direction of the $c$-axis reversed compared to the crystal cell $c$-axis), see Fig. S1. The length of the c-axis was increased to $40.0 \AA$ to create empty space between the slabs. A cell with the surface cell axes ( $a$ surf, $b_{\text {surf }}$ where $b_{\text {surf }}=a_{\text {surf }}$ ) doubled were used in the calculations, which led to $4 \mathrm{Al}$ atoms (or "surface sites") with a dangling bond that can be saturated by $\mathrm{CH}_{3}$ being present at the topmost surface. The atomic coordinates of the slabs (with or without adsorbents) were geometry optimized using a $3 \times 3 \times 1 \mathrm{k}$-point grid. Free energies were calculated from the computed vibrational mode frequencies of the optimized structures23 (Table S1).

The kinetics of the surface adsorption and desorption processes were simulated based on the quantum-chemical results. The adsorption rate was approximated from the impingement rate24,25 as no tight transition state is present along the internal reaction coordinate. The reverse reaction rates were derived based on the forward reaction rates to ensure that the thermodynamic equilibria can be reached as enough time has passed. The DFT-based surface reaction rates together with the gas phase reaction mechanism and rate for $\mathrm{C}_{2} \mathrm{H}_{6}$ formation from $\mathrm{CH}_{3}$ from literature 26,27,28,29,30 were employed in the kinetic model. The simulation of the kinetics was performed using the MATLAB SimBiology module31,32. The simulations of the amount of surface species as a function of time start from the surface fully covered by methyl groups $\left(4 \mathrm{CH}_{3}(\mathrm{~s})\right)$ at the pressure 100 pascal and the temperature $773 \mathrm{Kelvin}$. The pressure was 
held constant by the presence of non-interacting gas molecules (e.g. $\mathrm{N}_{2}$ ) plus molecules formed after desorption. The number of gas molecules was assumed to be much larger than the number of surface sites, i.e. the initial molar ratio of gas molecules/ $\mathrm{CH}_{3}(\mathrm{~s})$ was set to 50 . Two kinetic models are considered here. In the first model, the methyl radicals produced from the reactions are assumed to be completely purged away from the system at all times similar to when $\mathrm{H}_{2}, \mathrm{~N}_{2}$ and $\mathrm{Ar}$ is introduced between the TMA and $\mathrm{NH}_{3}$ pulse in the ALD cycle, while in the second model no extra pulse is used, i.e. no extra pulse between TMA and $\mathrm{NH}_{3}$, is assumed.

\section{Results and discussion}

In initial experiments, $\mathrm{H}_{2}$ pulses of different lengths were added between the TMA and $\mathrm{NH}_{3}$ pulses. Without addition of $\mathrm{H}_{2}$ pulse, the $\mathrm{C}$ content in an $\mathrm{AlN}$ film deposited at $480{ }^{\circ} \mathrm{C}$ was measured to be 3.1 at. \% from XPS analysis. Addition of an $\mathrm{H}_{2}$ pulse decreased the $\mathrm{C}$ content, Figure 1a. A short $\mathrm{H}_{2}$ pulse of $3.3 \mathrm{~s}$ decreases the $\mathrm{C}$ content to around 1 at. $\%$, which is the detection limit of carbon by XPS. It should be noted that simply doubling the purge length from $6 \mathrm{~s}$ to $12 \mathrm{~s}$ had no measurable effect on the carbon content in the film. The carbon content is at this low level also for longer durations of the $\mathrm{H}_{2}$ pulse. The same trend is also observed for a deposition temperature of $400{ }^{\circ} \mathrm{C}$ (Fig. 1a). For depositions made at lower temperature, $400{ }^{\circ} \mathrm{C}$, the carbon content is slightly lower without the $\mathrm{H}_{2}$ pulse $\left(2.6\right.$ at \%) as compared to $480{ }^{\circ} \mathrm{C}$ and the amount of carbon decreases to about 1.5 at. \% with the addition of a $\mathrm{H}_{2}$ pulse. The growth per cycle of the AlN films is stable upon increasing the length of the $\mathrm{H}_{2}$ pulse, Figure 1b. A slight decrease in the growth per cycle with increasing length of the $\mathrm{H}_{2}$ pulse could be observed. The composition from XPS of the film deposited at $480{ }^{\circ} \mathrm{C}$ with $19.5 \mathrm{~s} \mathrm{H} 2$ pulse was 49.1 at.\% $\mathrm{Al}, 46.0$ at.\% $\mathrm{N}, 4.3$ at.\% $\mathrm{O}$ and 0.6 at.\% $\mathrm{C}$ which gives a $\mathrm{Al} / \mathrm{N}$ ratio of 1.07. High resolution XPS spectra for Al 2p were fitted with two sub-peaks at $74.7 \mathrm{eV}$ and $75.5 \mathrm{eV}$ attributed to Al$\mathrm{N}$ and Al-O bonds respectively (Fig. 1c). For N 1s, the two sub-peaks were positioned at 397.9 $\mathrm{eV}$ and $399.4 \mathrm{eV}$ and were attributed to $\mathrm{N}-\mathrm{Al}$ and $\mathrm{N}-\mathrm{O}$ bonds, respectively (Fig. 1d). The O1s spectra shows the O-N and N-Al bonds, Fig. S2. The fitted peaks for Al 2p and N 1s are in line with previous XPS measurements on AlN films.33 

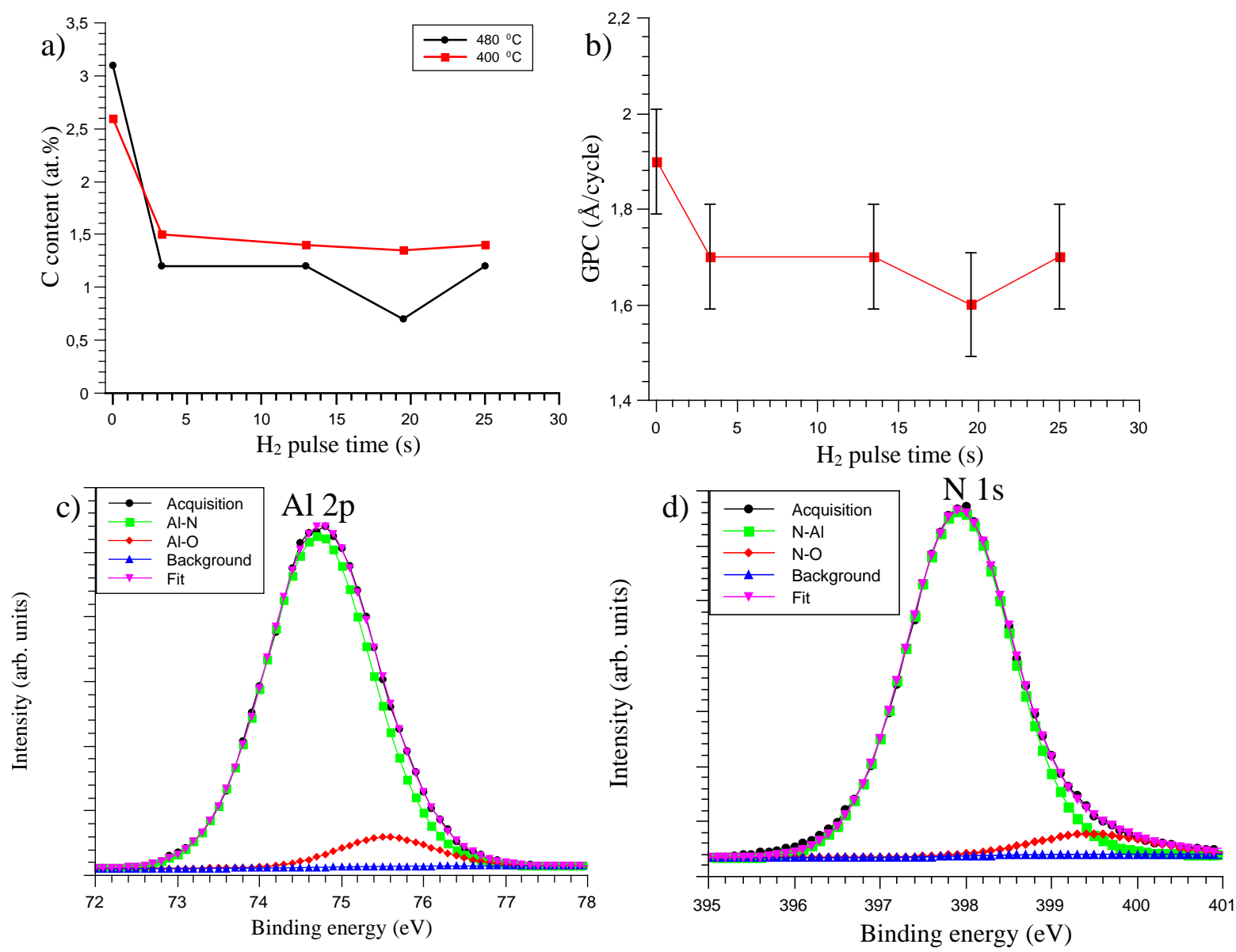

Figure 1: a) XPS measurement of the films with different pulse length of $\mathrm{H}_{2}$ showing decreasing $\mathrm{C}$ content upon increasing the $\mathrm{H}_{2}$ pulse time. b) the GPC of the films with different $\mathrm{H}_{2}$ pulse time deposited at $480{ }^{\circ} \mathrm{C}$. The high resolution XPS of the AlN with $19.5 \mathrm{~s} \mathrm{H}_{2}$ pulse deposited at $480{ }^{\circ} \mathrm{C} \mathrm{c}$ ) $\mathrm{Al} 2 \mathrm{p}$ and d) $\mathrm{N} 1 \mathrm{~s}$.

GIXRD measurement shows that the films consist of polycrystalline, hexagonal AlN and that the crystallinity of the films increases with the time for the $\mathrm{H}_{2}$ pulse, as seen that the intensity of the (100) plane more than triples when the $\mathrm{H}_{2}$ is added (black line) compared to without a $\mathrm{H}_{2}$ (red line) (Fig. 2a). The full width at half maximum value (FWHM) for the (100) plane also decreases from $0.657^{\circ}$ to $0.503^{\circ}$ upon addition of the $\mathrm{H}_{2}$ pulse, indicating a higher degree of crystallinity. This shows that adding a $\mathrm{H}_{2}$ pulse not only decreases the carbon content in the film, but also increases the crystallinity. Figure $2 \mathrm{~b}$ shows the morphology of the fine-grained polycrystalline nature of the AlN film with $19.5 \mathrm{~s} \mathrm{H}_{2}$ pulse deposited at $480{ }^{\circ} \mathrm{C}$, which was also seen from the GIXRD measurement, Fig. 2a. 


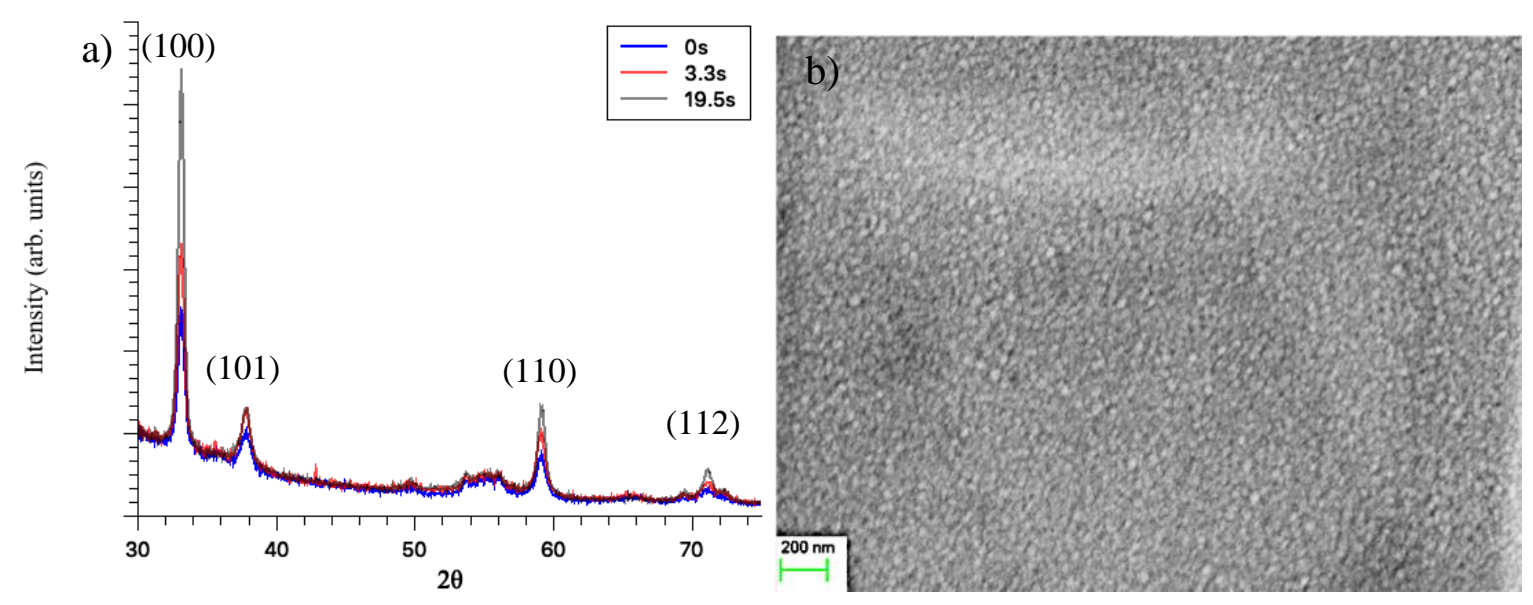

Figure 2: a) GIXRD of the films deposited at $480{ }^{\circ} \mathrm{C}$ on $\mathrm{Si}(100)$ with different lengths of $\mathrm{H}_{2}$ pulse between the TMA and $\mathrm{NH}_{3}$ pulse showing crystalline hexagonal AlN were the crystallinity increases upon longer $\mathrm{H}_{2}$ pulse. b) Top-view SEM of the AlN film deposited at $480{ }^{\circ} \mathrm{C}$ with $19.5 \mathrm{~s} \mathrm{H}_{2}$ pulse.

To test if the reduction in carbon content was due to a surface chemical reaction between surface methyl groups and the hydrogen gas, $\mathrm{N}_{2}$ and Ar were also tested as purge gas between the TMA and $\mathrm{NH}_{3}$ pulse. The pulse time for $\mathrm{H}_{2}, \mathrm{~N}_{2}$ and $\mathrm{Ar}$ was kept constant at $19.5 \mathrm{~s}$. XPS measurements show that the carbon content in the films is $1 \pm 0.4$ at $\%$ independent of which gas that is used. This suggests that carbon reduction by the added pulse between TMA and $\mathrm{NH}_{3}$ is not a chemical cleaning pulse, but rather acts to assist desorption and prevent re-adsorption of carbon containing species from the surface. Interestingly, the different gases used influence the crystallinity of the films. GIXRD measurements of films deposited with $\mathrm{H}_{2}, \mathrm{~N}_{2}$ and Ar show that the intensity of the (100) plane decreases when going from $\mathrm{H}_{2}$ to $\mathrm{N}_{2}$ and to $\mathrm{Ar}$ (Fig 3). Theta-2theta showed the same trend, Fig. S3. 


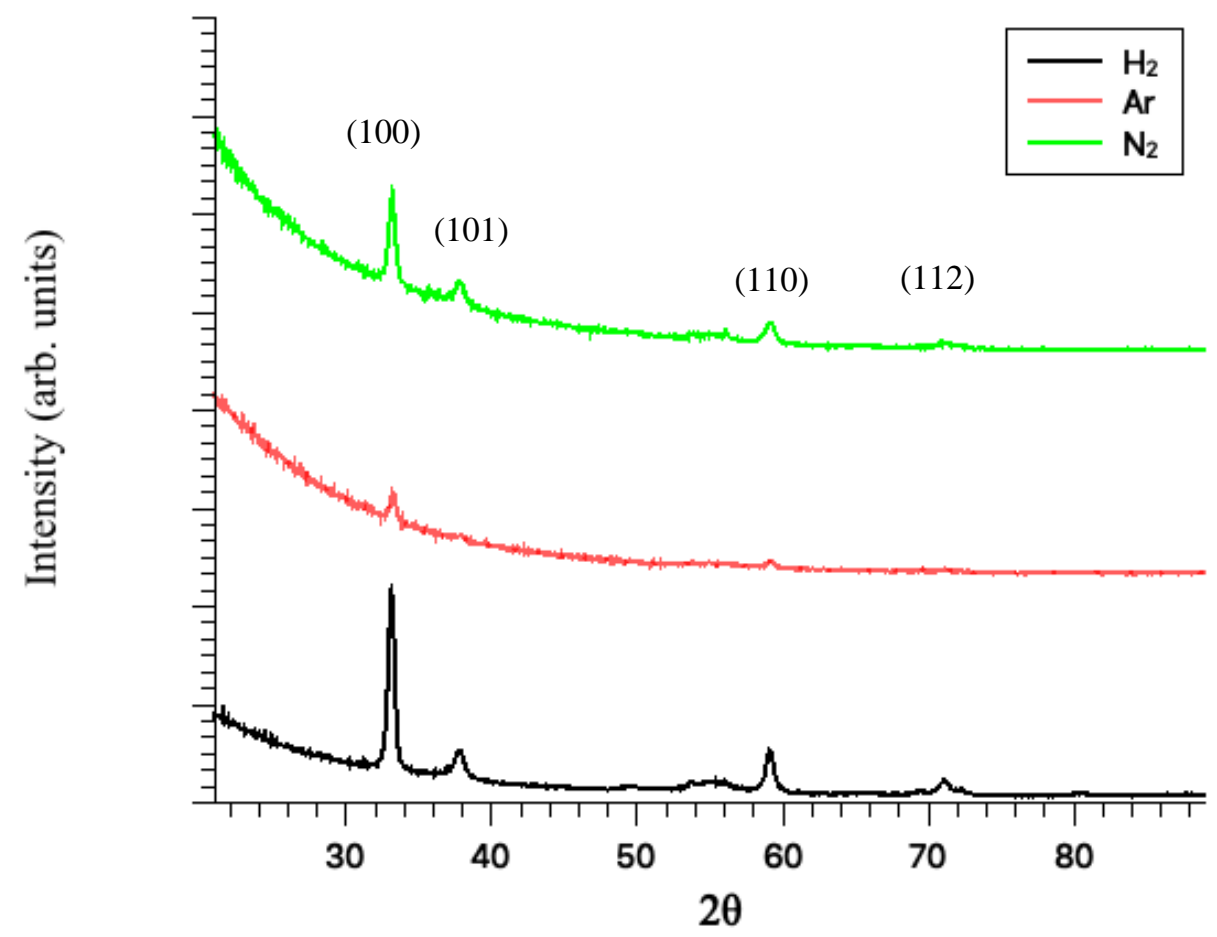

Figure 3: GIXRD of the films on $\mathrm{Si}(100)$ with $\mathrm{H}_{2}$, Ar and $\mathrm{N}_{2}$ as an extra pulse between the TMA and $\mathrm{NH}_{3}$ pulse deposited at $480^{\circ} \mathrm{C}$.

To study which carbon containing species are cleaned away by the extra pulse between the TMA and $\mathrm{NH}_{3}$ pulse, the AlN films were exposed to TMA vapor in an ALD chamber and the exhaust gases were analysed by mass spectrometry. Fig. S4 shows the MS graph for the background from the system without TMA supply into the chamber. From these experiments, it was noted that the intensity ratios (the region at a molecular weight of 15 and 28) between the detected masses differ between experiments with a continuous TMA flow and a TMA flow that is stopped and the chamber is left to purge, allowing the Ar purge gas more time to interact with the surface to mimic the extra pulse (Fig 4$)$. Figure 4 (0 min) shows the mass spectra for the continuous TMA flow, the highest intensity was collected at three regions at a molecular weight (M.W.) of 15, 28 and 40. The last region with a M.W. of 40 corresponds to Ar, which is used as purge and carrier gas in the system. The first region shows predominantly M.W. of 15 and 16. These masses could correspond to $\mathrm{CH}_{3}$ and $\mathrm{CH}_{4}$ respectively. This would be in line with previous experimental results showing that TMA decomposes at around $330{ }^{\circ} \mathrm{C}$ by splitting of a methyl group12. The second region with high intensity is found at a M.W. of around 27 is attributed to ${ }_{x} H C-\mathrm{CH}_{x}$ molecules. The same three high intensity regions are present when the TMA supply into the chamber is stopped and the Ar purge gas has more time to interact with the surface (Fig. 4). The overall intensities decrease when the TMA flow is stopped for all regions except for the second region at a M.W. of 27 (Fig. 4), which increases upon 
longer Ar exposure time. Interestingly, the intensities between the peaks changes when the TMA flow is stopped and Ar purge gas have more time to interact with the methyl terminated surface (Fig. 4), compared to the case with a continuous TMA flow. The M.W. of 15 has a higher intensity compared to 16 , which is the opposite to when continuous TMA flow into the chamber. This indicates a higher probability to form $\cdot \mathrm{CH}_{3}$ radicals when the Ar purge gas is given more time to interact with the surface, Fig. 4 and Fig. S5. The intensity for M.W. 27 increases by approximately $67 \%$ for experiments when the TMA flow is stopped for 15 min compared to continuous flow of TMA into the chamber, Fig. 4. This suggests favoured formation of ${ }_{x} \mathrm{HC}-\mathrm{CH}_{x}$ over formation of $\cdot \mathrm{CH}_{3}$ radicals with increasing Ar purge time.

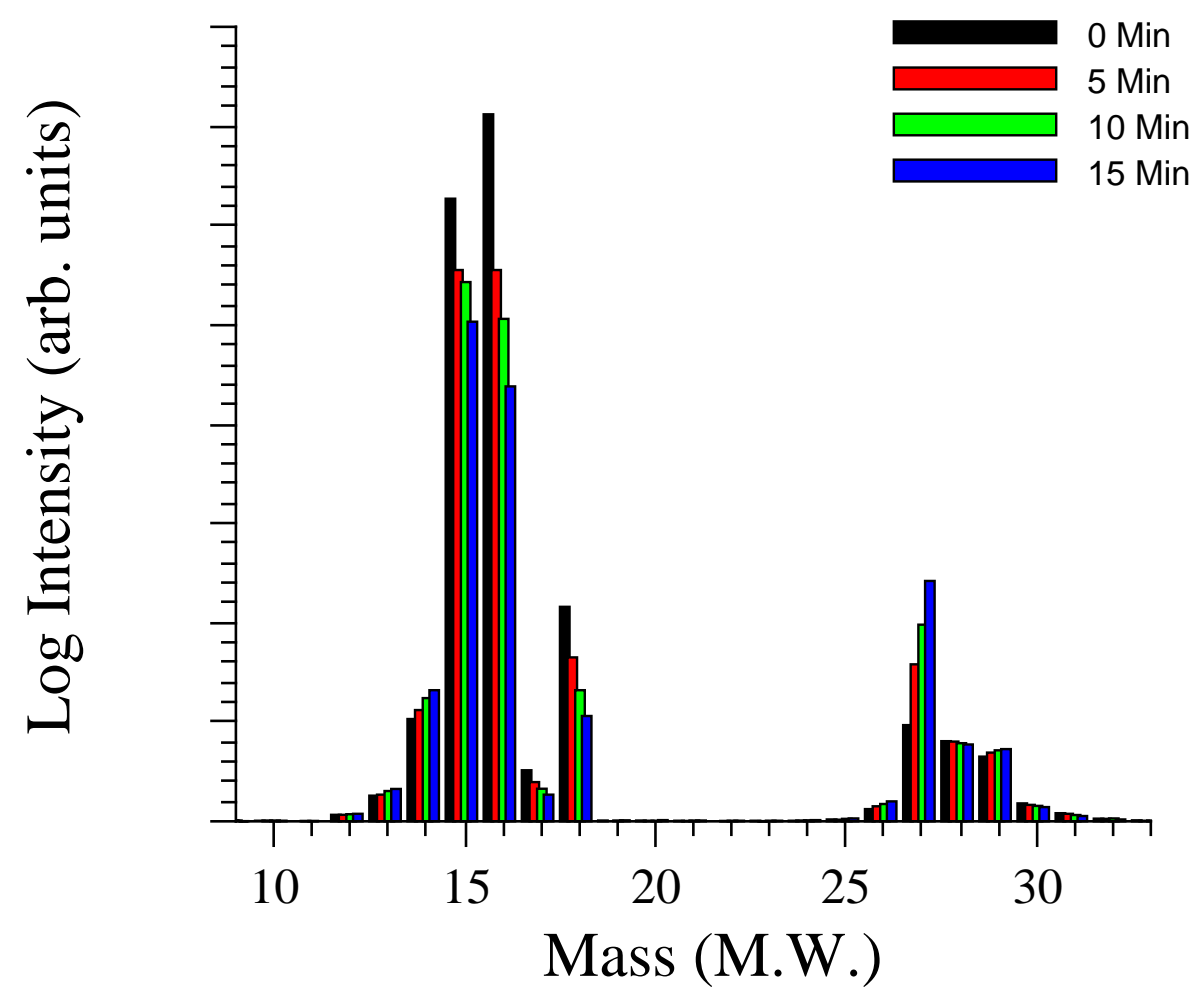

Figure 4: The MS graph for when TMA is supplied continuously in the chamber ( 0 min) and when the TMA supply is cut showing different species being formed over longer Ar exposure time.

Kinetics simulations were used to obtain an atomistic level understanding of the surface chemistry (Fig. 5). Starting from a fully saturated surface (i.e. in the model $4 \mathrm{CH}_{3}$ groups at 4 surface sites), the first methyl group is seen to quickly desorb from the fully occupied surface. This could be expected since the desorption of a $\mathrm{CH}_{3}$ from a fully occupied surface is actually exergonic (and with a negligible reaction barrier), see Table S1, which is likely due to the repulsion between the closely-packed surface-adsorbed methyl groups. The desorption rates 
become significantly slower with increasing number of empty sites on the surface. This is to be expected since the repulsion between the adsorbed groups decreases as the number of empty sites increases for the most densely packed surfaces. The desorption rates were also found to increase with increasing temperature which is also observed experimentally (Fig. 1a). Figure 5a shows the kinetics when a pulse of inert gas is added between TMA and NH3. Adding the extra pulse between the TMA and $\mathrm{NH}_{3}$ pulse will remove the methyl radicals from above the surface, which facilitates a more accelerated desorption of the carbon groups by suppressing the re-adsorption process. With no added pulse of inert gas between TMA and $\mathrm{NH}_{3}$ (Fig. 5b), the methyl groups previously released from the surface can either become re-adsorbed on the empty sites or converted to $\mathrm{C}_{2} \mathrm{H}_{6}$ molecules, which is manifested by the persistence of the dominantly $\mathrm{CH}_{3}$-terminated surface in Figure $5 \mathrm{~b}$. This was also seen in the mass spectra (Fig. 4); more ${ }_{x} \mathrm{HC}-\mathrm{CH}_{\mathrm{x}}$ species are formed from the desorbed methyl groups when the TMA supply is stopped.
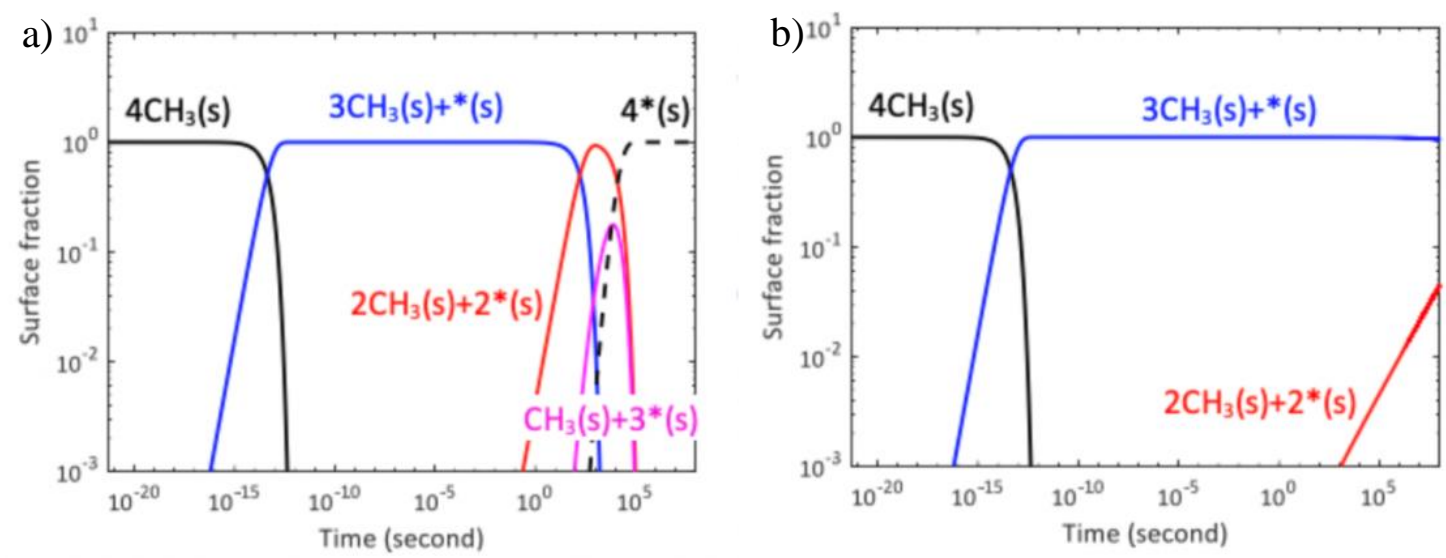

Figure 5: The simulated surface fractions as a function of time, a) with a pulse of inert gas between TMA and $\mathrm{NH}_{3}$ and $\mathrm{b}$ ) without a pulse of inert gas between TMA and $\mathrm{NH}_{3}$, at $100 \mathrm{~Pa}$ and $500{ }^{\circ} \mathrm{C}$.

The $\mathrm{C}$ incorporation in the film versus time as estimated from the computed surface coverage is shown in Figure. 6. The re-adsorption process leads to a significant increase in the carbon incorporation in the film (Fig. 6b). On the other hand, when a pulse is introduced between TMA and $\mathrm{NH}_{3}$, the re-adsorption process is suppressed, and the desorption dominates, resulting in the reduction of the carbon incorporation in the film (Fig. 6a). This correlates with the experimental results in Figure 1a. 

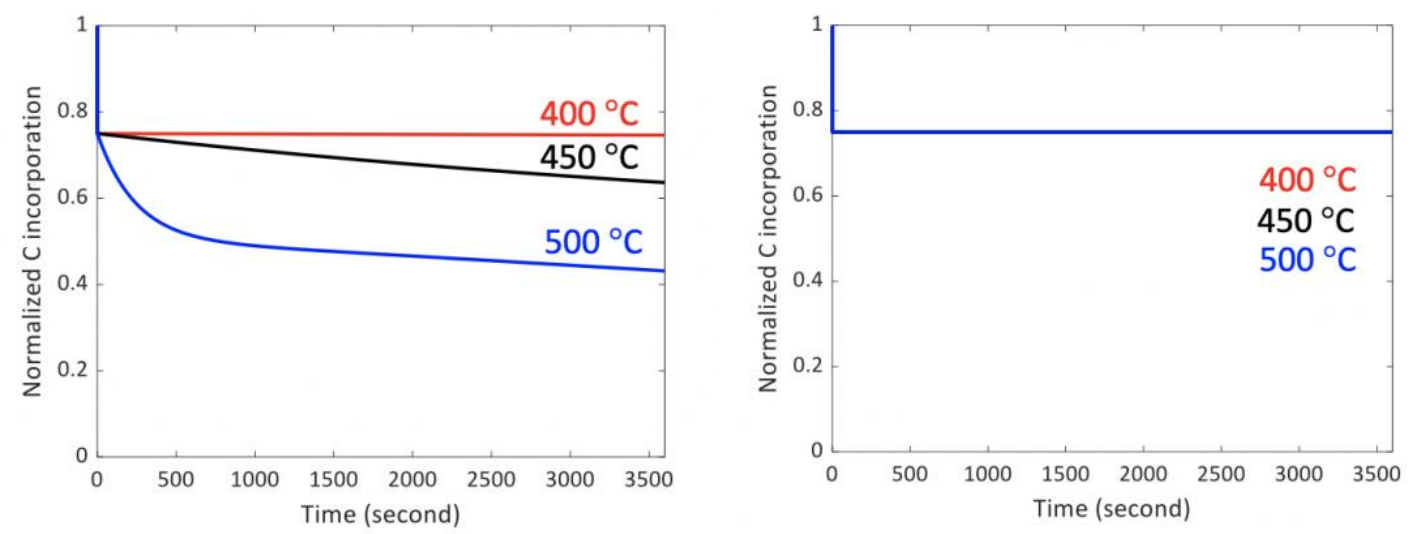

Figure 6: The simulations of time depended carbon incorporation at 400,450 and $500{ }^{\circ} \mathrm{C}$ with a pulse of inert gas between TMA and $\mathrm{NH}_{3}$ a) and without inert gas pulse b).

We believe that the extra pulse between TMA and $\mathrm{NH}_{3}$ gives surface methyl groups enough time to desorb from the surface and prevents their re-adsorption. In the kinetic simulations (Fig. S6) the methyl groups on the surface desorb quickly and with time these methyl groups react and form ethane $\left(\mathrm{C}_{2} \mathrm{H}_{6}\right)$. The same observations were made experimentally where the mass spectrometer showed that when Ar purge gas has more time to interact with the $-\mathrm{CH}_{3}$ terminated surface, $\mathrm{C}_{2} \mathrm{H}_{\mathrm{x}}$ molecules are formed. But when a continuous flow of precursors was used then Ar purge gas had short time to interact with the $-\mathrm{CH}_{3}$ terminated surface and mostly $\mathrm{CH}_{\mathrm{x}}$ molecules were detected. The extra pulse introduced between TMA and $\mathrm{NH}_{3}$ would not only give the surface terminated methyl groups time to desorb but it would also purge away the desorbed methyl groups from the surface. This would facilitate a faster desorption rate of the carbon groups by suppressing the re-adsorption pathway according to our kinetic model. Without the extra gas pulse the desorbed surface methyl groups could re-adsorb before the $\mathrm{NH}_{3}$ is introduced into the chamber which could lead to them being trapped in the film. Carbon impurities in semiconductor graded materials have always been a problem when deposited at high temperature and we believe that this ABC-type pulsed process (were A is TMA pulse, B is the extra pulse and $\mathrm{C}$ is $\mathrm{NH}_{3}$ pulse) could possibly be the solution to accomplish high temperature ALD depositions with low $\mathrm{C}$ impurities. 


\section{Summary and Conclusions}

A high temperature thermal ALD-like CVD approach with time-resolved precursor supply for AlN was explored by adding an extra pulse of $\mathrm{H}_{2}, \mathrm{~N}_{2}$ or Ar between the TMA and $\mathrm{NH}_{3}$ pulses to investigate if that could change the surface chemistry and lower the $\mathrm{C}$ content in the film. We show that by adding an extra purge gas pulse perpendicular to the substrate surface, the carbon impurities in the film decreased drastically to approximately 1 at.\% giving a $\mathrm{Al} / \mathrm{N}$ ratio of 1.07. The surface chemistry and the role of the extra pulse between TMA and $\mathrm{NH}_{3}$ was investigated with mass spectrometry, quantum chemical and kinetic modelling. It was found from the modelling that the most loosely bound surface methyl groups can desorb quickly with negligible reaction barrier. The added pulse between TMA and $\mathrm{NH}_{3}$ is believed to clean the region just above the surface from desorbed methyl groups, promoting additional desorption and suppressing any re-adsorption of the desorbed methyl groups. It was found both experimentally and from the calculations that the desorption of the surface methyl groups increases with increasing temperature. Mass spectrometry measurements show that more $\mathrm{xHC}$ $\mathrm{CH}_{\mathrm{x}}$ species, compared to $\mathrm{CH}_{\mathrm{x}}$ species, are formed with longer purge times. The growth of the AlN film was somewhat dependent of the extra pulse time were longer pulses gave smaller growth rate which were attributed to less $\mathrm{C}$ impurities in the film. The type of gas used as the pulse between TMA and $\mathrm{NH}_{3}$ was found to have a stronger impact on the crystallinity were the crystallinity of the films increased when going from Ar, $\mathrm{N}_{2}$ to $\mathrm{H}_{2}$.

\section{Acknowledgements}

This project was supported by the Swedish Foundation for Strategic Research (SSF) through the project "Time-resolved low temperature CVD for III-nitrides" (SSF-RMA 15-0018). LO acknowledges financial support from the Swedish Government Strategic Research Area in Materials Science on Functional Materials at Linköping University (Faculty Grant SFO Mat LiU no. 2009 00971) and from the Swedish Research Council (VR). Supercomputing resources were provided by the Swedish National Supercomputer Centre (NSC) via the Swedish National Infrastructure for Computing (SNIC). 


\section{References}

(1) Taniyasu, Y.; Kasu, M.; Makimoto, T. An Aluminium Nitride Light-Emitting Diode with a Wavelength of 210 Nanometres. Nature 2006, 441 (7091), 325-328.

(2) Li, J.; Nam, K. B.; Nakarmi, M. L.; Lin, J. Y.; Jiang, H. X.; Carrier, P.; Wei, S. H. Band Structure and Fundamental Optical Transitions in Wurtzite AlN. Appl. Phys. Lett. 2003, 83 (25), 5163-5165.

(3) Chen, Z.; Newman, S.; Brown, D.; Chung, R.; Keller, S.; Mishra, U. K.; Denbaars, S. P.; Nakamura, S. High Quality AlN Grown on SiC by Metal Organic Chemical Vapor Deposition. Appl. Phys. Lett. 2008, 93 (19), 91-94.

(4) Van Bui, H.; Nguyen, M. D.; Wiggers, F. B.; Aarnink, A. A. I.; De Jong, M. P.; Kovalgin, A. Y. SelfLimiting Growth and Thickness- And Temperature- Dependence of Optical Constants of ALD AlN Thin Films. ECS J. Solid State Sci. Technol. 2014, 3 (4), P101-P106.

(5) Liu, X.; Ramanathan, S.; Lee, E.; Seidel, T. E. Atomic Layer Deposition of Aluminum Nitride Thin Films from Trimethyl Aluminum (TMA) and Ammonia. MRS Proc. 2004, 811, 1-6.

(6) Riihelä, D.; Ritala, M.; Matero, R.; Leskelä, M.; Jokinen, J.; Haussalo, P. Low Temperature Deposition of AlN Films by an Alternate Supply of Trimethyl Aluminum and Ammonia. Chem. Vap. Depos. 1996, 2 (6), 277-283.

(7) Dendooven, J.; Deduytsche, D.; Musschoot, J.; Vanmeirhaeghe, R. L.; Detavernier, C. Conformality of Al2O3and AlN Deposited by Plasma-Enhanced Atomic Layer Deposition. J. Electrochem. Soc. 2010, $157(4), 0-5$.

(8) Ozgit, C.; Donmez, I.; Alevli, M.; Biyikli, N. Self-Limiting Low-Temperature Growth of Crystalline AlN Thin Films by Plasma-Enhanced Atomic Layer Deposition. Thin Solid Films 2012, 520 (7), 27502755.

(9) Ozgit-Akgun, C.; Goldenberg, E.; Okyay, A. K.; Biyikli, N. Hollow Cathode Plasma-Assisted Atomic Layer Deposition of Crystalline AlN, GaN and $\mathrm{Al} \times \mathrm{Ga} 1_{-\mathrm{x}} \mathrm{N}$ Thin Films at Low Temperatures. J. Mater. Chem. C 2014, 2 (12), 2123-2136.

(10) Bosund, M.; Sajavaara, T.; Laitinen, M.; Huhtio, T.; Putkonen, M.; Airaksinen, V. M.; Lipsanen, H. Properties of AlN Grown by Plasma Enhanced Atomic Layer Deposition. Appl. Surf. Sci. 2011, 257 (17), 7827-7830.

(11) Nepal, N.; Qadri, S. B.; Hite, J. K.; Mahadik, N. A.; Mastro, M. A.; Eddy, C. R. Epitaxial Growth of AlN Films via Plasma-Assisted Atomic Layer Epitaxy. Appl. Phys. Lett. 2013, 103 (8).

(12) Yamashita, S.; Watanuki, K.; Ishii, H.; Shiba, Y.; Kitano, M.; Shirai, Y.; Sugawa, S.; Ohmi, T. Dependence of the Decomposition of Trimethylaluminum on Oxygen Concentration. J. Electrochem. Soc. 2011, 158 (2), 93-96.

(13) Zhang, Z.; Pan, Y.; Yang, J.; Jiang, Z.; Fang, H. Experimental Study of Trimethyl Aluminum Decomposition. J. Cryst. Growth 2017, 473, 6-10.

(14) Erwin, S. C.; Lyons, J. L. Atomic Layer Epitaxy of Aluminum Nitride: Unraveling the Connection between Hydrogen Plasma and Carbon Contamination. ACS Appl. Mater. Interfaces 2018, 10 (23), 20142-20149.

(15) Perdew, J. P.; Burke, K.; Ernzerhof, M. Generalized Gradient Approximation Made Simple. Phys. Rev. Lett. 1996, 77, 3865-3868. 
(16) Perdew, J. P.; Burke, K.; Ernzerhof, M. Erratum: Generalized Gradient Approximation Made Simple. Physical Review Letters. Gaussian, Inc: Wallingford CT 1997, p 1396.

(17) Grimme, S.; Antony, J.; Ehrlich, S.; Krieg, H. A Consistent and Accurate Ab Initio Parametrization of Density Functional Dispersion Correction (DFT-D) for the 94 Elements H-Pu. J. Chem. Phys. 2010, 132 (15).

(18) Kresse, G.; Furthmüller, J. Efficient Iterative Schemes for Ab Initio Total-Energy Calculations Using a Plane-Wave Basis Set. Phys. Rev. B - Condens. Matter Mater. Phys. 1996, 54 (16), 11169-11186.

(19) Blöchl, P. E. Projector Augmented-Wave Method. Phys. Rev. B 1994, 50 (24), 17953-17979.

(20) Kresse, G.; Joubert, D. From Ultrasoft Pseudopotentials to the Projector Augmented-Wave Method. Phys. Rev. B - Condens. Matter Mater. Phys. 1999, 59 (3), 1758-1775.

(21) Shiraishi, K. A New Slab Model Approach for Electronic Structure Calculation of Polar Semiconductor Surface. J. Phys. Soc. Japan 1990, 59 (10), 3455-3458.

(22) Dai, J.; Song, Y. First Principles Calculations on the Hydrogen Atom Passivation of TiO2 Nanotubes. RSC Adv. 2016, 6 (23), 19190-19198.

(23) McQuarrie, D. A.; Simon, J. D. Molecular Thermodynamics; University Science Books, 1999.

(24) Sukkaew, P.; Kalered, E.; Janzén, E.; Kordina, O.; Danielsson, Ö.; Ojamäe, L. Growth Mechanism of SiC Chemical Vapor Deposition: Adsorption and Surface Reactions of Active Si Species. J. Phys. Chem. C 2018, 122 (1), 648-661.

(25) Sukkaew, P.; Danielsson, Ö.; Ojamäe, L. Growth Mechanism of SiC CVD: Surface Etching by H2, H Atoms, and HCl. J. Phys. Chem. A 2018, 122 (9), 2503-2512.

(26) Baulch, D. L.; Pilling, M. J.; Cobos, C. J.; Cox, R. A.; Esser, C.; Frank, P.; Just, T.; Kerr, J. A.; Troe, J.; Walker, R. W.; et al. Evaluated Kinetic Data for Combustion Modelling. J. Phys. Chem. Ref. Data 1992, 21 (3), 411-734.

(27) Baulch, D. L.; Pilling, M. J.; Cobos, C. J.; Cox, R. A.; Esser, C.; Frank, P.; Just, T.; Kerr, J. A.; Troe, J.; Walker, R. W.; et al. Evaluated Kinetic Data for Combustion Modelling. Supplement I. J. Phys. Chem. Ref. Data 1992, 21 (3), 411-734.

(28) Pintassilgo, C. D.; Loureiro, J.; Cernogora, G.; Touzeau, M. Methane Decomposition and Active Nitrogen in a N2-CH4 Glow Discharge at Low Pressures. Plasma Sources Sci. Technol. 1999, 8 (3), 463-478.

(29) Baulch, D. L.; Pilling, M. J.; Cobos, C. J.; Cox, R. A.; Frank, P.; Hayman, G.; Just, T.; Kerr, J. A.; Murrells, T.; Troe, J.; et al. Evaluated Kinetic Data for Combustion Modeling. Supplement II. J. Phys. Chem. Ref. Data 1994, 23 (6), 847-848.

(30) NIST Chemistry WebBook, SRD69 https://webbook.nist.gov/chemistry/form-ser/.

(31) MATLAB R2015a. The MathWorks Inc.: Natick, MA, USA 2015.

(32) Erdtman, E.; Andersson, M.; Lloyd Spetz, A.; Ojamäe, L. Simulations of the Thermodynamics and Kinetics of NH3 at the RuO2 (110) Surface. Surf. Sci. 2017, 656 (June 2016), 77-85.

(33) Motamedi, P.; Cadien, K. Applied Surface Science XPS Analysis of AlN Thin Films Deposited by Plasma Enhanced Atomic Layer Deposition. Appl. Surf. Sci. 2014, 315, 104-109. 